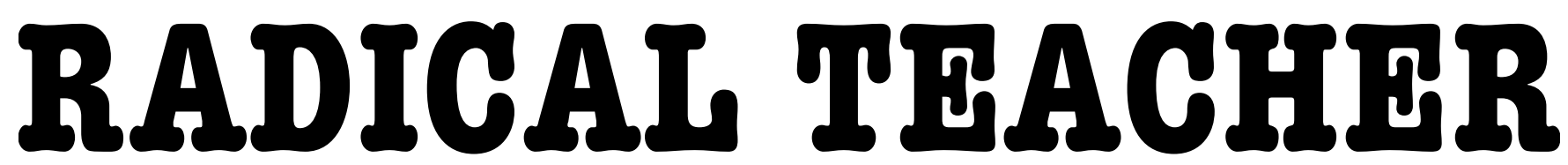
A SOCIALIST, FEMINIST, AND ANTI-RACIST JOURNAL ON THE THEORY AND PRACTICE OF TEACHING

\author{
Poetry \\ To My Students
}

by Nina Pick

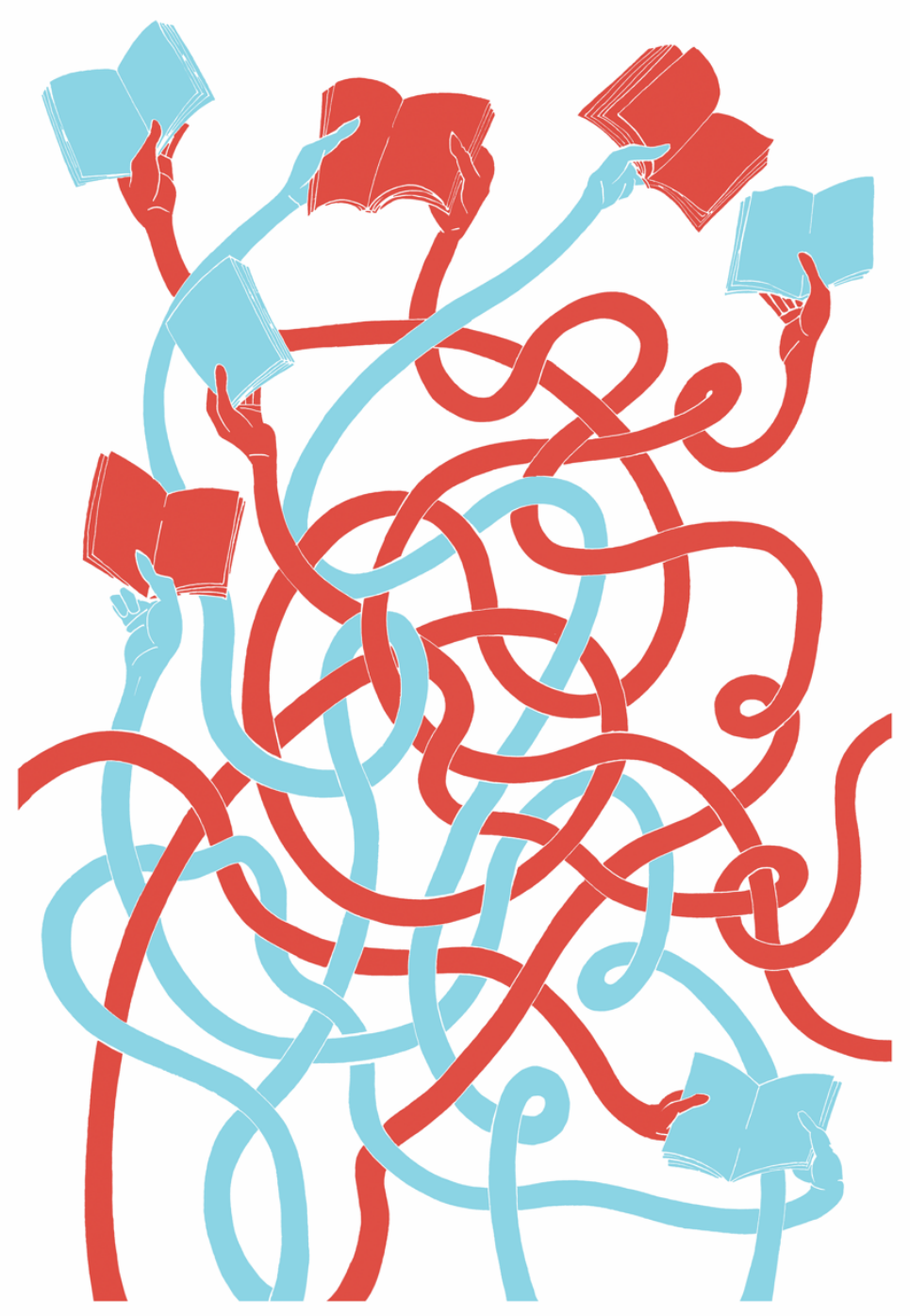

JOSH MACPHEE, 2014 (VIA JUST SEEDS) 


\section{To My Students}

I'm so sorry,

we are teaching you all the wrong lessons,

repeating the fictions of anxiety

replicated on computer screens.

I'm sorry that we drag you

out of your body and into your head,

wrenching you from your gentle center,

your own innate knowing.

I'm sorry that we have taken your inborn

love of the earth and replaced it

with videogames, and then fed you

pharmaceuticals to numb your grief.

I'm sorry that we weld you to reason

at the expense of intuition,

homework at the expense of heartwork,

science at the expense of mythos,

and capitalism at the expense of everything.

And I'm so sorry

that our voices have silenced the wisdom

at a stone's center, in the heart of a seed,

in the mouths of animals and rivers,

in the stars' far-reaching, time-traveling light.

Go out of the classroom and into the forest.

There you will find your true teachers

shimmering with answers to questions

we never taught you to ask.

Let the rain wash you free

of your human education.

Follow the light of those stars.

This work is licensed under a Creative Commons Attribution-Noncommercial-No Derivative Works 3.0 United States License.

This journal is published by the University Library System of the University of Pittsburgh as part of its D-Scribe Digital Publishing Program, and is cosponsored by the University of Pittsburgh Press. 